\title{
Chapter 5 \\ Migration of Radioactive Cesium to Water from Grass and Fallen Leaves
}

\author{
Hirokuni Yamanishi, Masayo Inagaki, Genichiro Wakabayashi, \\ Sin-ya Hohara, Tetsuo Itoh, and Michio Furukawa
}

\begin{abstract}
The TEPCO Fukushima Daiichi Nuclear Power Plant accident in March 2011 led to high amounts of emitted radioactive Cs being deposited on land by both rainwater and snowfall. In addition, a significant amount of Cs was deposited on the surface of leaves, and after the accident, both trees and grasses absorbed radioactive Cs through their roots. In order to assess the effect on water sources, it is therefore important to evaluate the amount of radioactive Cs migrating to the water from both grass and fallen leaves.

A number of samples of clover, dandelion, and mugwort were collected from the Yamakiya elementary school in Kawamata-machi, Date-gun, Fukushima-ken in May 2013 and May 2014. Fallen leaves were also sampled from the wood adjoining the school. Measurement of the Cs content in water was carried out by placing the sample in water for over 400 days at $10-30{ }^{\circ} \mathrm{C}$. The radioactive $\mathrm{Cs}$ content was measured using the HPGe detector. In the case of grass, the amount of migration to water was saturated after about 120 days. The saturation levels of migration rate to water varied with kinds of grass in the range of $0.2-0.8$. The migration rate for fallen leaves was not larger than 0.13 . In addition, after leaching from grass or fallen leaves into water, the absorption of radioactive Cs to soil was observed, and therefore, migration would be limited to a small area.
\end{abstract}

Keywords Fallen leaves • Grass • Migration - Radioactive cesium • Waste decontamination - Water

H. Yamanishi $(\bowtie) \bullet$ M. Inagaki $\bullet$ G. Wakabayashi $\bullet$ S.-y. Hohara $\bullet$ T. Itoh

Atomic Energy Research Institute, Kinki University, 3-4-1 Kowakae, Higashi-osaka,

Osaka 577-8502, Japan

e-mail: yamanisi@kindai.ac.jp

M. Furukawa

Mayor of Kawamata-machi, Fukushima-ken, 30, Gohyakuda, Kawamata-machi, Date-gun,

Fukushima-ken 960-1492, Japan 


\subsection{Introduction}

A large amount of radioactive material was released by the nuclear power plant accident at the TEPCO Fukushima Daiichi site (1F site) in March 2011 [1]. The radioactive particles were transported by the prevailing wind and were deposited on the ground by both rain and snowfall. Due to these factors, the level of radiation in surrounding areas has been raised through the presence of radioactive material on the ground. As radiocesium is a source of both external exposure and internal exposure, its environmental behavior is of particular interest. Radiocesium adheres strongly to clays in the surface soil [2], and a very small amount is absorbed upon contact with water. Radiocesium was also deposited on the surface of leaves. In addition, following the deposition on the soil surface, trees and grasses absorbed the radiocesium in the soil through their roots.

Due to their long half-lives, Cs-134 (2 years) and Cs-137 (30 years) are responsible for the ongoing presence of radioactive materials outside the $1 \mathrm{~F}$ site, even 4 years after the event. In the contaminated area outside the $1 \mathrm{~F}$ site, decontamination work is now underway on residential land spaces and public facilities. During this process, the topsoil is removed and collected, and dried grass and fallen leaves are collected as contaminated waste. The waste for decontamination is stored in a flexible impermeable $1-\mathrm{m}^{3}$ bag and kept in a temporary depot for subsequent decontamination.

We are particularly interested in determining the quantity of radiocesium that migrates to water from grasses, fallen leaves, and soil. The environmental behavior of radiocesium was previously studied following the Chernobyl nuclear plant accident [3]. However, it is difficult to apply the result to Fukushima, as the environmental conditions such as soil type, precipitation amount, and temperature are very different at the two sites. The annual rainfall is approximately $1166 \mathrm{~mm}$ in Fukushima but only $621 \mathrm{~mm}$ in Pripyat, the town of Chernobyl. Due to the higher quantity of rainfall in Fukushima, it is possible that radiocesium is transferred through water. In addition, it should be considered that the chemical form of radiocesium that deposits in Fukushima is different to that deposited in Chernobyl. It is therefore necessary to use samples collected in Fukushima to study the environmental behavior of radiocesium in this area.

In order to assess the effect on water sources, it is therefore considered important to evaluate the amount of radiocesium migrating to the water from grass and fallen leaves. We herein report a process for the determination of the Cs content in grass and fallen leaves and in water following leaching. Samples collected in Fukushima will be used for the studies. We expect that it will be possible to use the obtained results for the prediction of radiocesium behavior in the environment. 


\subsection{Materials and Methods}

\subsubsection{Sample Collection}

Environmental samples for this study were collected from the grounds of the Yamakiya elementary school, Kawamata-machi, Fukushima-ken, Japan. Fallen radiocesium gave a high topsoil Cs-137 content of $50 \mathrm{~Bq} / \mathrm{g}$ in May 2011 [4]. Accuracy was expected to be improved using grass collected from the contamination site, rather than grass grown in a laboratory. In addition, at the contamination site, fallen leaves contained radiocesium on their surface due to deposition. Samples of clover, dandelion, pine needles, and mugwort were collected in May 2013 and May 2014. Fallen leaves were also collected in the forest that adjoins the school. In May 2013 and May 2014, the measured ambient dose rates at $1 \mathrm{~m}$ above ground level are $0.5-1.2$ and $0.2-0.8 \mu \mathrm{Sv} / \mathrm{h}$, respectively.

Kawamata-machi is located approximately $40 \mathrm{~km}$ to the northwest of the $1 \mathrm{~F}$ site. Following the accident, as the estimated annual dose was expected to exceed $20 \mathrm{mSv}$, the Yamakiya area in the southeast of Kawamata-machi was appointed a planned evacuation zone on April 22, 2011. The staff at the Atomic Energy Research Institute of Kinki University investigated the environmental radiation in cooperation with Kawamata-machi and began the collection of data, which contributed to understanding the radiation situation and aided in the discussions relating to the implementation of control measures $[4,5]$.

\subsubsection{Sample Preparation}

In order to prepare the plant samples for measurement, they were first preprocessed. First, the roots were removed from the grass samples, as they held soil that was contaminated with radiocesium. Other samples were washed with water to remove the soil particles on the surface of the samples. After washing, the samples were dried either in air or in an oven at $60{ }^{\circ} \mathrm{C}$. The dried samples $(15 \mathrm{~g})$ were chopped finely $(<1 \mathrm{~cm}$ length) and were placed into a U-8 container for measurement. The radiocesium concentration in each sample was measured using a hyperpure germanium semiconductor detector (HPGe detector).

\subsubsection{Radiocesium Migration to Water}

The measured samples (15 g) were divided into four equally sized portions and each portion placed into a water-permeable bag $(95 \times 70 \mathrm{~mm})$, which was weaved with composite fiber composed of polyethylene, polypropylene, and polyester. The four bags containing the samples were soaked in water $(500 \mathrm{~mL})$ in a plastic 
container $(18 \times 13 \times 5 \mathrm{~cm})$, which was tightly closed, and allowed to stand for over 400 days. After this time, the resulting contaminated water was filtered, collected, and weighed. As the radiocesium concentrations in the sample were low, it was desirable to remove as much water as possible from the sample to precisely measure radioactivity. This was initially achieved by means of an evaporating dish and mantle heater. The dried matter was scraped away from the surface of the dish by washing with water $(10 \mathrm{~mL})$ and was moved to a U-8 container. The sample was then dried further by evaporation using an infrared oven. The radiocesium contents of samples were measured using the HPGe detector to give the radioactivity of the radiocesium that migrated to water from the plant samples.

Using the sample collected in May 2014, a similar experiment was conducted, which compares the migration rate to water using both deionized water and rainwater. The soaking period was 10-135 days, and the temperature was controlled at $25^{\circ} \mathrm{C}$.

\subsubsection{Radiocesium Deposition in Soil}

Radiocesium migrates to water from grass by means of soaking. However, water is often in contact with soil, and as the clay minerals present in soil strongly adsorb radiocesium, it is expected that the radiocesium in water can be deposited in soil. We therefore decided to investigate this by exposing soil to a solution containing radiocesium for 3 days, and the variations in radiocesium concentration in the solutions were measured. The solution required for this experiment was prepared using fallen leaves gathered at the Yamakiya Elementary School. Radiocesium was leached from the leaves by means of an ultrasound bath. The radiocesium concentration was then increased by reduction in the water content using an evaporating dish and a heating mantle. The radiocesium concentration in the solution was determined using an HPGe detector. A solution containing radiocesium (100 mL) was added to samples of dry field soil (10 or $30 \mathrm{~g})$, and the resulting mixture was left to stand at $20-25^{\circ} \mathrm{C}$ for either $14 \mathrm{~h}$ or 3 days. After this time, the aqueous solution was filtered to remove all soil particles and collected. The resulting residual radiocesium concentrations of all four solutions (10 g, $14 \mathrm{~h}),(30 \mathrm{~g}, 14 \mathrm{~h})$, (10 g, 3 days), and (30 g, 3 days) were measured using an HPGe detector.

\subsection{Results and Discussion}

We first examined the sample collected in May 2013. The radioactivities of Cs137 in the dried sample $(15 \mathrm{~g}$ ) before soaking were calculated to be $5.9 \pm 0.2 \mathrm{~Bq}$, $2.6 \pm 0.2 \mathrm{~Bq}, 18.5 \pm 0.4 \mathrm{~Bq}, 3.0 \pm 0.1 \mathrm{~Bq}, 102 \pm 2 \mathrm{~Bq}$, and $369 \pm 3 \mathrm{~Bq}$, for clover, pine needles, mugwort, dandelion, fallen leaves (broad leaf), and fallen leaves (needle leaf), respectively. The amounts of Cs-137 eluted from each sample 
Fig. 5.1 Change in migration rate from grass with the elapsed days

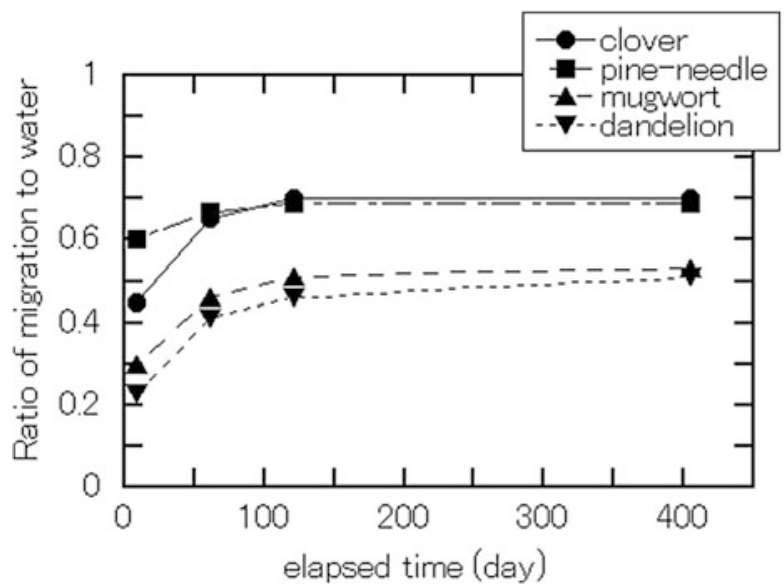

after soaking for 9 days were calculated to be $2.7 \pm 0.1 \mathrm{~Bq}, 1.60 \pm 0.04 \mathrm{~Bq}$, $5.5 \pm 0.2 \mathrm{~Bq}, 0.70 \pm 0.03 \mathrm{~Bq}, 8.2 \pm 0.2 \mathrm{~Bq}$, and $6.3 \pm 0.2 \mathrm{~Bq}$, with an approximate 10 -fold difference between the maximum and minimum values obtained. The migration rate is defined as the ratio of the radioactivity that migrated to water to the radioactivity of the sample before soaking. These migration rates were calculated to be $0.45 \pm 0.03,0.60 \pm 0.04,0.30 \pm 0.01,0.23 \pm 0.01,0.08 \pm 0.002$, and $0.017 \pm 0.001$. Fallen leaves have ratios in the range of $0.02-0.08$ while grass exhibited larger ratios of $0.23-0.60$.

After collection of the water, it was poured once more into the plastic container and was left to stand at $10-30{ }^{\circ} \mathrm{C}$. This operation was repeated three times over different timeframes, more specifically, 50, 60, and 280 days, corresponding to 60 , 120, and 400 days after beginning the soaking period, respectively. Figures 5.1 and 5.2 show the variation in migration rate over time. As shown in Fig. 5.1, in the case of grass, almost all the radiocesium which can be migrated had migrated to water after 60 days. In addition, it could be seen that after 120 days, little migration was observed, and so the total migration rate for 120 days was comparable to that for 400 days. In contrast, as shown in Fig. 5.2, the migration rate for fallen leaves was small, although an increase in migration rate even after 400 days was observed. This difference between grass and fallen leaves may be due to a number of reasons. Firstly, it must be considered that the radiocesium present in grass had been absorbed through the roots from the soil. This component of radiocesium might be present within the grass tissue due to weak adsorption, and thus may migrate to water. This would therefore result in a large migration rate for grass. In contrast, the radiocesium released following the accident was deposited on the surface of fallen leaves and was not absorbed through the roots. In addition, the radiocesium present on the fallen leaves did not migrate as easily to water, as the fallen leaves had been exposed to rain, and their surfaces washed before sampling. The migration rate shown in Fig. 5.2 is therefore small. 
Fig. 5.2 Change in migration rate from fallen leaves and soil with the elapsed days

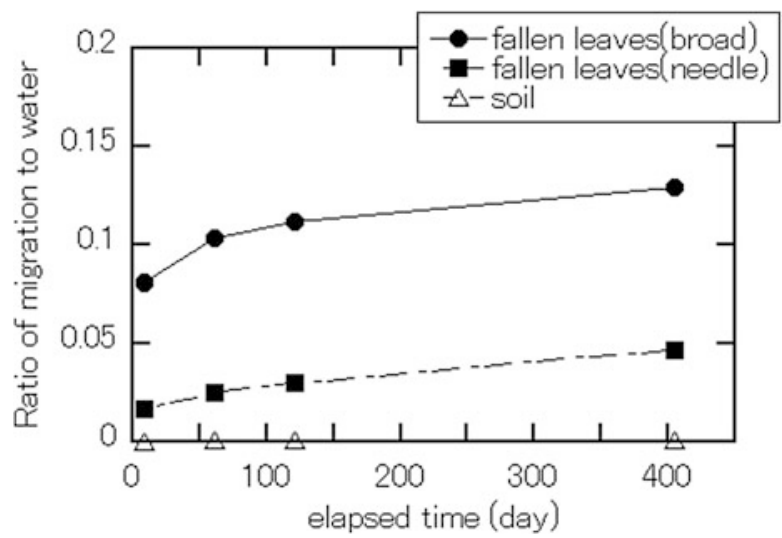

Figure 5.2 also shows the migration rate of radiocesium from dry soil (90 g) to water $(500 \mathrm{~mL})$. It was observed that the migration rate was very low. In addition, the migration rates increased over time, with a rate of $(3.5 \pm 0.1) \times 10^{-4}$ recorded after 10 days and $(1.2 \pm 0.1) \times 10^{-3}$ after 400 days.

Using the sample collected on May 2014, the migration rate for deionized water was compared with that obtained for rainwater. These samples were soaked in water for 10-135 days at $25^{\circ} \mathrm{C}$. As can be seen in Fig. 5.3, the differences between the two specifications of water were very small. Figures 5.4 and 5.5 show the variation in migration rate over time. The increasing trends of total migration have a similar pattern to Figs. 5.1 and 5.2. The migration rates from clover or pine needle were larger than that from mugwort, while the migration rate from fallen broad leaves was larger than that from fallen needle leaves.

Finally, Fig. 5.6 shows the results of the residual rate to solution (i.e., the ratio of concentration after soaking to concentration before soaking). The concentration of Cs-137 in the solution before the adsorption experiments was $0.177 \pm 0.004 \mathrm{~Bq} / \mathrm{g}$. The residual rate in the case of $10 \mathrm{~g}$ soil was $0.29 \pm 0.02$ after soaking for $14 \mathrm{~h}$ and $0.17 \pm 0.01$ after soaking for 3 days. The residual rate in the case of $30 \mathrm{~g}$ soil was calculated as $0.11 \pm 0.01$ after soaking for $14 \mathrm{~h}$ and $0.07 \pm 0.01$ after soaking for 3 days. These data demonstrate that the residual rate decreases according to both the quantity of soil and according to the number of days in the soaking period. This is likely due to the large quantities of soil present in the area, and thus the radiocesium could not be transported through a large area. This would also not be possible even through migration to water, as the radiocesium would be rapidly adsorbed into the soil. 
Fig. 5.3 Comparison of water, deionized water $(\mathrm{dw})$ and rain water (rw)

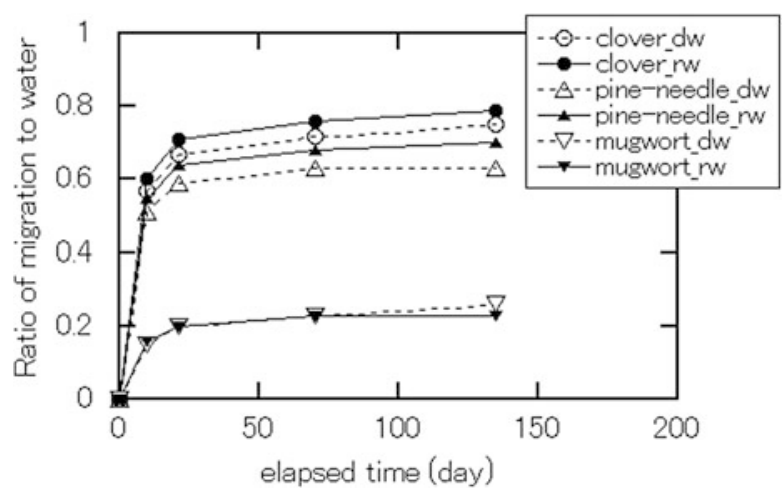

Fig. 5.4 Change in migration rate from grass with the elapsed days (using the sample May 2014)

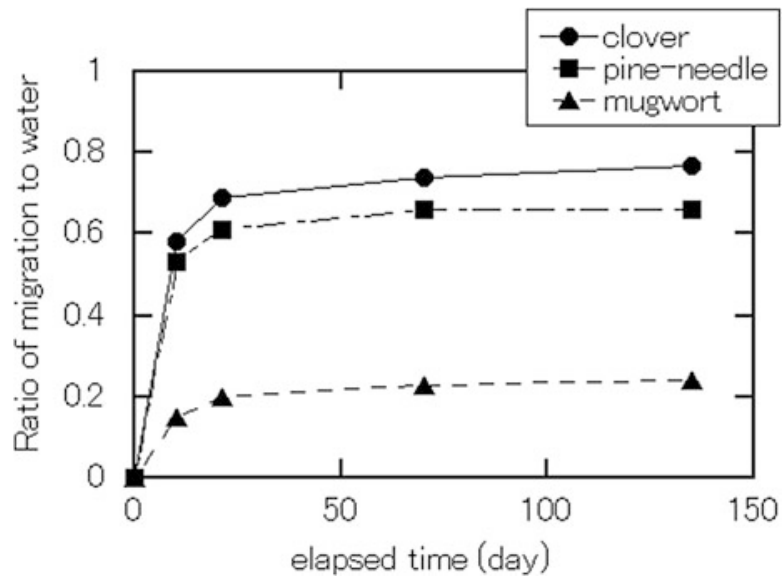

Fig. 5.5 Change in migration rate from fallen leaves and soil with the elapsed days (using the sample May 2014)

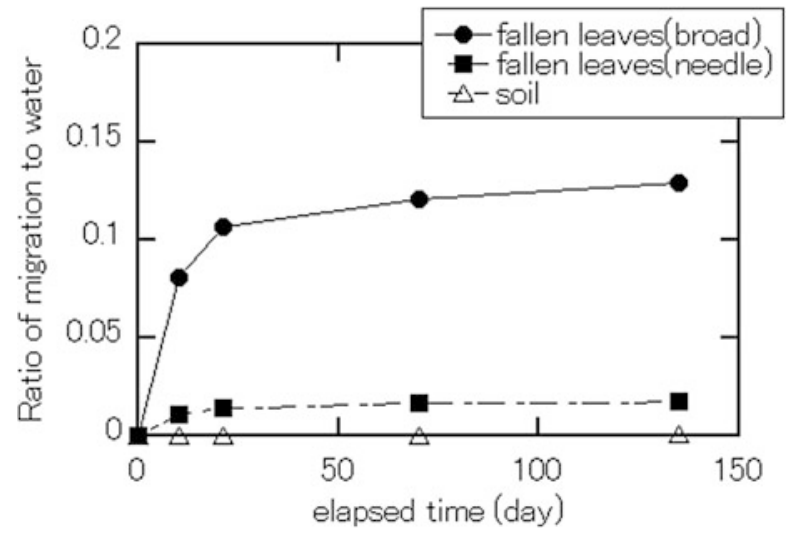


Fig. 5.6 Experimental result of the residual rate to solution

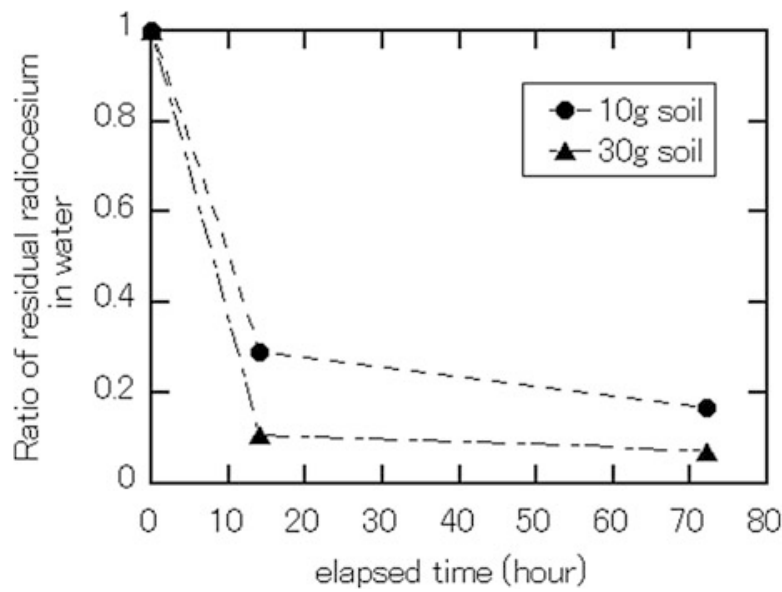

\subsection{Conclusion}

We obtained migration rates of radiocesium from samples of grass or fallen leaves (collected from Kawamata-machi, Fukushima-ken) soaked in water, with the rates for grass being larger than those for fallen leaves are. It is thought that the radiocesium present in grass exists in an easily transported form for rapid permeation within the grass tissue. In contrast, the radiocesium deposited on the surface of fallen leaves was exposed to rain for a long period before sampling, thus leading to a lower migration rate. As regarding grass and fallen leaves, there is no difference between at the test site and at other sites; the migration rates obtained in this study can be considered general values rather than specific values. We also investigated the effects of soaking contaminated soil in water and found that migration rates were low but increased gradually over time. In addition, it was observed that migration rates in deionized water were comparable with those in rainwater.

The adsorption of radiocesium into soil was studied using a solution containing radiocesium that had migrated to water from fallen leaves. The amount of radiocesium adsorbed by the soil depended on the quantity of soil. It is therefore expected that under natural conditions, the radiocesium, which is capable of migrating to water, can be easily adsorbed by the soil, and therefore cannot be transported over long distances. It may be possible to apply the results of this study for the prediction of radioactive cesium behavior in the environment.

Open Access This chapter is distributed under the terms of the Creative Commons Attribution Noncommercial License, which permits any noncommercial use, distribution, and reproduction in any medium, provided the original author(s) and source are credited. 


\section{References}

1. Chino M, Nakayama H, Nagai $\mathrm{H}$ et al (2011) Preliminary estimation of release amount of I-131 and Cs-137 accidentally discharged from the Fukushima Daiichi Nuclear Power Plant into the atmosphere. J Nucl Sci Technol 48:1129-1134

2. Tsukada H, Toriyama K, Yamaguchi N et al (2011) Behavior of radionuclides in soil-plant system. Jpn J Soil Sci Plant Nutr 82:408-418 (in Japanese)

3. Report of the Chernobyl Forum Expert Group 'Environment' (2006) Environmental consequences of the chernobyl accident and their remediation: twenty years of experience. IAEA, Vienna

4. Yamanishi H, Hohara S, Wakabayashi G et al (2013) Survey of environmental radiation in Kawamata-machi, Fukushima-Prefecture. Radioisotopes 62:259-268, in Japanease

5. Itoh T, Furukawa M, Sugiura N et al (2011) Survey of environmental radiation in Kawamatamachi, Fukushima-ken. Annual report of Atomic Energy Research Institute, Kinki University 48:3-9 (in Japanese) 